\title{
Testis Sparing Surgery in Pediatric Population
}

\author{
(1) Tuncay Toprak ${ }^{1}$, (1) Çağrı Akın Şekerci² \\ 1 University of Health Sciences Turkey, Fatih Sultan Mehmet Training and Research Hospital, Clinic of Urology, Istanbul, Turkey \\ 2 Marmara University Pendik Training and Research Hospital, Clinic of Urology, Istanbul, Turkey
}

\begin{abstract}
In this review, it is aimed to illuminate the place of testicular sparing surgery in childhood testicular tumors in the light of current literature. The importance of organ-sparing surgery is highlighted because a significant portion of childhood testicular tumors are benign and organ-sparing surgery reduces morbidity without affecting disease-related survival. Testis sparing surgery can be considered as an alternative to radical inguinal orchiectomy in synchronous bilateral testicular tumors, metachronous contralateral tumors, and in the presence of normal solitary testis if preoperative testosterone level is normal and the tumor size is less than $30 \%$ of the testicular volume. However, definite recommendations could not be determined due to the lack of literature data.

Keywords: Child, testicular tumor, testis sparing surgery
\end{abstract}

\section{Introduction}

Testicular tumors constitute $1-2 \%$ of all childhood solid tumors $(1,2,3)$ and more than $74 \%$ of them are benign $(4)$. The incidence of childhood testicular tumors is $0.52 / 100,000$ (5). The incidence of testicular tumors in the postpubertal period is 10 times higher than in children under 12 years of age. The incidence of testicular tumor peaks especially under the age of 3 and during adolescence (15-18 years) $(2,6)$. Undescended testis, testicular atrophy, infertility, contralateral testicular germ cell tumor, familial testicular germ cell tumor and gonadal dysgenesis are among the risk factors for malignant testicular tumor in children. The risk in undescended testis increases 4.8 times (7). It was reported that the risk increases 3.5 times in children who were operated on for undescended testis after the age of 10 (8). In the prospective population-based study conducted by Pettersson et al. (9), it was observed that the least risky group was children who were operated on before the age of $6(R R=2.02)$. It was reported that the risk in unilateral undescended testes operated on before the age of 10-12 years was reduced by 2-6 times compared to those operated on later (10). Testicular tumors seen before puberty are generally observed in a single histological type, unlike adult testicular tumors (11) and seminomas are not observed in the prepubertal period (12). $1 p$ deletion, structural defects in $2 p$ and $3 p$ chromosomes, and loss of $6 q$, which are not common in adults, are common in pediatric germ cell tumors. According to the Prepubertal Testicular Tumor Registry (PTTR), the main testicular tumors are yolk sac tumors and then teratomas. Although extensive database analyzes indicated that teratomas were more common, the results were inconsistent as these data were not limited to prepubertal children $(13,14)$. As a result, yolk sac tumors and teratomas are the most common testicular tumors seen before puberty. According to PTTR data, the age at diagnosis is 16 months for yolk sac tumors and 13 months for teratomas $(15,16)$.

\section{Clinical Findings}

The most important clinical finding is painless scrotal mass or stiffness $(50-95 \%)(1,17,18)$. In addition, testicular mass can be detected after trauma (3\%), with detection of hydrocele (10\%), with the presence of testicular pain or torsion $(21 \%)$, or incidentally (10-53\%). Early puberty symptoms and gynecomastia can also be counted among the first findings.

\section{Diagnosis}

The diagnosis is usually made by scrotal ultrasound (USG) after taking anamnesis and performing physical examination. Physical examination should be done very carefully in terms of differential diagnosis of epididymitis, hydrocele, testicular torsion, orchitis, and inguinal hernia. Testicular tumors may be associated with hydrocele at a rate of $15-20 \%$ (15). Although ultrasonography has a high sensitivity in detecting an intra- or extra-testicular 
scrotal mass, its sensitivity is low in the differentiation of malignancy. In intratesticular masses, its sensitivity is over $90 \%$ (19), but its specificity is $44.4 \%$ (20). It is the imaging method that should be chosen first because it is easily accessible, reliable and non-invasive. In case of malignancy, computer tomography or magnetic resonance imaging of abdomen, pelvis and lungs are performed.

\section{Tumor Markers}

Tumor markers can be helpful in distinguishing preoperative histological types and in postoperative follow-up. Alphafetoprotein (AFP) is the equivalent of fetal albumin. AFP is produced in fetal yolk sac and later in fetal liver cells. Increased AFP values can be found in pregnancy, hepatocellular cancer, cirrhosis, non-seminatous germ cell tumors and viral hepatitis (21). AFP is also frequently increased (90\%) in yolk sac tumors and has a half-life of 5 days. Human chorionic gonadotropin $(\beta-\mathrm{hCG})$ is found to be elevated in choriocarcinoma and embryonal cell carcinoma, but these tumors are not common in the prepubertal period. Therefore, measurement of $\beta$-hCG in childhood testicular tumors does not help the diagnosis much (22). The half-life of $\beta$-hCG is 24 hours. AFP is an important tumor marker in the prepubertal period, while $\beta$-hCG is a marker in rarer cases (2). AFP is physiologically high in healthy infants up to 8 months of age. It reaches adult levels up to 1 year of age. Therefore, care should be taken in associating AFP levels with tumors $(2,23)$. $\mathrm{LH}, \mathrm{FSH}$, testosterone and urinary 17-ketosteroid levels should be examined in testicular tumors seen with early puberty findings.

\section{Classification}

Classification is made as primary, secondary and metastatic tumors according to their histopathological features. Benign primary testicular tumors are consisted of epidermoid and dermoid cysts of epithelial origin, Leydig and Sertoli cell tumors of sex cord-stromal origin, and teratomas of germ cell origin. Teratomas are the most common benign tumors. Primary testicular tumors with malignant character are germ cell-derived embryonal carcinoma, yolk sac tumors, choriocarcinoma, gonadoblastoma, and paratesticular rhabdomyosarcoma. Yolk sac tumors are the most common malignant testicular tumors. Secondary tumors include testicular lymphoma and leukemia. Neuroblastoma and Wilms tumor can metastasize to the testis in childhood.

\section{Treatment}

The basic approach in the surgical treatment of malignant testicular tumor is radical inguinal orchiectomy. There is no place for scrotal approach and testicular biopsy except in some special cases. In benign tumors, testis sparing surgery (TSS) is the basic approach.

\section{- Radical Inguinal Orchiectomy}

Radical inguinal orchiectomy is the basic approach in testicular tumor with clinically malignant character or diagnosed as malignant in frozen examination (24). The fact that the testicles are not a vital organ, sperm bank and hormonal replacement therapy are among the reasons supporting this surgery. However, after inguinal orchiectomy, castration may develop at a young age and sexual functions may decrease. It can cause psychological effects as well as endocrine and fertility related problems.

\section{- Testis Sparing Surgery}

Testis-sparing surgery was first performed by Richie (25) in a patient with bilateral seminoma. Pediatric TSS was performed in a patient with cystic teratoma in 1983 (26). The belief that the prevalence of a benign mass originating from the testis was low and that biopsy from a malignant mass would lead to tumor seeding caused the treatment choice to be limited to radical orchiectomy until the 1990s (27). Conservative surgical interventions in testicular tumors have come to the fore, with improvements in oncological outcomes of testicular tumors, long lifespan due to cancer, understanding of the prevalence of benign testicular tumors in childhood, and the increasing number of non-palpable masses with the widespread use of testicular USG $(28,29)$. The high diagnostic value of the frozen examination, the increase in the quality of life, and the preservation of endocrine functions have made the approach that preserves the testis to be preferred. Studies are continuing to strengthen the use of TSS in patients in whom the other testicle is intact, not only in children with bilateral testicular tumors or a single testicle that has lost the other testicle for other reasons. Because there is a risk of losing one of the testicles over time due to trauma, infection or testicular tumor $(30,31,32)$. In addition, in a series of 2.800 patients in whom radical inguinal orchiectomy was performed with the preliminary diagnosis of testicular tumor, it was observed that the cause was benign tumor in $31 \%$ of the patients (33). Before this surgery, serum AFP and $\beta$-hCG levels should be measured and scrotal ultrasonography should be performed, and peroperative frozen biopsy should be sent $(24,34)$. TSS should be considered teratoma, gonadal stromal tumors and epidermoid cysts in the prepubertal period (24). According to the results of TSS performed in Leydig cell tumors; local recurrence was observed in only one patient during an average follow-up period of 4-8 years, and there was no local or distant recurrence other than that $(35,36,37,38)$. Oncological follow-up is not required in prepubertal patients with Leydig cell tumor, gonadoblastoma, teratoma, epidermoid cyst and juvenile granulosa cell tumor. However, patients with yolk sac tumor and undifferentiated stromal tumor should undergo examination for metastatis and be followed up closely. Although the European Association of Urology (EAU) guidelines do not recommend TSS in patients in whom the contralateral testis is healthy, they recommend that TSS can be performed in patients with synchronous bilateral tumors, metachronous contralateral tumors, or solitary testicles with a tumor volume of less than $30 \%$ of the testicular volume and a normal testosterone level before the operation. Since approximately $82 \%$ of these testicles have testicular intraepithelial neoplasia (TIN), adjuvant radiotherapy (20 Gy) is recommended after surgery (39). In the "European Consensus Conference on Diagnosis and Treatment of Germ Cell Cancer" 2008 meeting, it was stated that testicular sparing surgery might be an alternative procedure to radical orchiectomy in the presence of synchronous bilateral or metachronous contralateral tumors or in patients with normal 
preoperative testosterone levels with solitary testis, as in the EAU guidelines. It was reported that the presence of TIN should be well evaluated and adjuvant radiotherapy should be given in unilateral testicular tumors (40). In a 73-patient study conducted by the German Testicular Cancer group, 18 Gy radiotherapy was given to patients with TIN who underwent TSS, and it was observed that disease-free survival was achieved in $98.6 \%$ of the patients in a 91 -month follow-up, that $85 \%$ of the patients did not need testosterone replacement therapy, and that fertility was preserved in $50 \%$ of the patients (41). Local recurrence or distant metastasis was not detected in any patient with pediatric testicular teratoma and epidermoid cyst who underwent TSS with a 22-year follow-up period $(34,42)$. In a comprehensive study by Heidenreich et al. (27), in the 37-year follow-up of 120 patients with testicular epidermoid cyst, no local recurrence or distant metastasis was found in any patient. Apart from epidermoid cyst and Leydig cell tumor, TSS seems to be an appropriate approach in patients with tunica albuginea cysts, intraparenchymal cysts, adenomatoid tumor, dermoid cyst, inflammatory pseudotumor, postinflammatory fibrosis, granulomatous inflammation, hemangioma, and Sertoli cell tumor. The fact that these benign lesions of the testis are masses that can be easily diagnosed without causing confusion in the frozen incision examination facilitates the decision of the surgeon peroperatively $(2,3,12,13)$. In a study conducted with 24 patients with negative serum markers and a mean age of 10.7 years who underwent radical or partial orchiectomy due to unifocal and unilateral intratesticular tumor; while TSS was found sufficient for tumors that were benign in the final pathological examination and did not contain germ cells; lesions containing active germ cell tumor structure were not suitable for TSS (43). In the same study, it was reported that the frozen pathological examination was compatible with the final pathological examination and did not miss patients that were not suitable for TSS. Of the patients who were found to be unsuitable for TSS, it was found that they were statistically older (17.1 vs. 9.3 years; $p=0.029)$. It was stated that $95 \%(n=19)$ of the children who had a mass less than $2 \mathrm{~cm}$ had the appropriate pathology for TSS (43).

\section{Surgical Technique}

For TSS, after passing the layers with an inguinal incision, the external oblique aponeurosis is opened up to the internal ring, and the cord structures are suspended and held with a soft vascular clamp or turned with a tourniquet. The testis is delivered through the inguinal incision, the mass is palpated, and the testis is placed in crushed ice. Routine use of intraoperative USG is another recommended point in order to detect a small mass or a mass focus other than the one previously defined in the testis $(44,45)$. The tunica vaginalis is opened over the mass and an incision is made around the mass. Excisional biopsy is applied to the mass without disturbing the capsule integrity and the tissue is sent for frozen biopsy examination. The edges of the tunica albuginea are then approximated with a thin, absorbable suture. If the frozen result is benign, the clamp is removed and bleeding is controlled, the tunica vaginalis is closed, the testis is placed in the scrotum, the layers are closed and the operation is completed. In case of malignancy, orchiectomy is performed if the patient's other testis is intact. Despite the finding of malignancy in an individual with intact contralateral testis, there is currently insufficient knowledge to perform TSS. In this case, there is a risk of local recurrence, multifocal disease, tumor cell cultivation and progression. In patients in whom there is bilateral masses or a mass in the solitary testis that is malignant as a result of the frozen examination, multiple biopsies are taken from the parenchymal tissue remaining after the mass excision, and another concomitant malignancy focus or TIN is tried to be determined $(46,47)$. Long-term disease-free survival can be achieved with tumor enucleation, biopsy from the tumor bed, frozen examination, peripheral parenchyma biopsy, radiotherapy to the remaining tissue, and close follow-up.

\section{Conclusion}

Most prepubertal testicular tumors are benign, but all scrotal masses should be evaluated for malignancy. If a palpable scrotal mass is detected, scrotal USG should be performed and tumor markers should be checked. Today, radical inguinal orchiectomy is the gold standard method in the treatment of testicular tumors. TSS seems to be an alternative method, especially in masses that are thought to be benign in childhood, and the authors recommend that the possible benefits and risks should be discussed with the parents of appropriate patients. If malignancy is detected in the frozen section examination, radical inguinal orchiectomy should be continued.

\section{Acknowledgements}

Publication: The results of the study were not published in full or in part in form of abstracts.

Contribution: There is not any contributors who may not be listed as authors.

Conflict of Interest: No conflict of interest was declared by the authors.

Financial Disclosure: The authors declared that this study received no financial support.

\section{Ethics}

Peer-review: Internally peer-reviewed.

\section{Authorship Contributions}

Supervision: Ç.A.Ş., Concept: T.T., Ç.A.Ş., Design: T.T., Ç.A.Ş., Data Collection or Processing: T.T., Ç.A.Ş., Analysis or Interpretation: T.T., Ç.A.Ş., Literature Search: T.T., Writing: T.T., Ç.A.Ş.

\section{References}

1. Akiyama S, Ito K, Kim W], et al. Prepubertal testicular tumors: a singlecenter experience of 44 years. J Pediatr Surg 2016;51:1351-1354.

2. Ross JH. Prepubertal testicular tumors. Urology 2009;74:94-99.

3. Brosman SA. Testicular tumors in prepubertal children. Urology 1979;13:581-588.

4. Pohl HG, Shukla AR, Metcalf PD, et al. Prepubertal testis tumors: actual prevalence rate of histological types. J Urol 2004;172:2370-2372.

5. Coppes MJ, Rackley R, Kay R. Primary testicular and paratesticular tumors of childhood. Med Pediatr Oncol 1994;22:329-340.

6. Alanee S, Shukla A. Paediatric testicular cancer: an updated review of incidence and conditional survival from the Surveillance, Epidemiology and End Results database. BJU Int 2009;104:1280-1283. 
7. Dieckmann KP, Pichlmeier U. Clinical epidemiology of testicular germ cell tumors. World J Urol 2004;22:2-14.

8. Walsh TJ, Dall'Era MA, Croughan MS, et al. Prepubertal orchiopexy for cryptorchidism may be associated with lower risk of testicular cancer. J Urol 2007;178:1440-1446.

9. Pettersson A, Richiardi L, Nordenskjold A, et al. Age at surgery for undescended testis and risk of testicular cancer. N Engl J Med 2007; 356:1835-1841.

10. Wood HM, Elder JS. Cryptorchidism and testicular cancer: separating fact from fiction. J Urol 2009;181:452-461.

11. Ross JH, Kay R. Prepubertal testis tumors. Rev Urol 2004;6:11-18.

12. Mostfi F. Tumors of the male genital system. Atlas of Tumor Pathology 1973:114-119.

13. Sugita Y, Clarnette TD, Cooke-Yarborough C, et al. Testicular and paratesticular tumours in children: 30 years' experience. Aust N Z J Surg 1999;69:505-508.

14. Rushton HG, Belman AB. Testis-sparing surgery for benign lesions of the prepubertal testis. Urol Clin North Am 1993;20:27-37.

15. Javadpour N. Principles and management of testicular cancer: Thieme-Stratton Corp; 1986.

https://www.sciencedirect.com/science/article/abs/pii/ S0022534717457053

16. Ross JH, Rybicki L, Kay R. Clinical behavior and a contemporary management algorithm for prepubertal testis tumors: a summary of the Prepubertal Testis Tumor Registry. J Urol 2002;168:1678-1679.

17. Taskinen S, Fagerholm R, Aronniemi J, et al. Testicular tumors in children and adolescents. J Pediatr Urol 2008;4:134-137.

18. Agarwal PK, Palmer JS. Testicular and paratesticular neoplasms in prepubertal males. J Urol 2006;176:875-881.

19. Benson C. The role of ultrasound in diagnosis and staging of testicular cancer. Semin Urol; 1988.

20. Coret A, Leibovitch I, Heyman Z, et al. Ultrasonographic evaluation and clinical correlation of intratesticular lesions: a series of 39 cases. Br J Urol 1995;76:216-219.

21. Perkins GL, Slater ED, Sanders GK, Prichard JG. Serum tumor markers. Am Fam Physician 2003;68:1075-1088.

22. Palmer J, Morris K, Steinberg G, Kaplan W. Testicular, sacrococcygeal, and other tumors. Comprehensive Textbook of Genitourinary Oncology. Philadelphia: Lippincott Williams \& Wilkins, 2000.

23. Grady RW. Current management of prepubertal yolk sac tumors of the testis. Urol Clin North Am 2000;27:503-508.

24. Metcalfe PD, Farivar-Mohseni H, Farhat W, et al. Pediatric testicular tumors: contemporary incidence and efficacy of testicular preserving surgery. J Urol 2003;170:2415-2416.

25. Richie J. Simultaneous bilateral tumors with unorthodox management. World J Urol 1984;2:74.

26. Marshall S, Lyon RP, Scott MP. A conservative approach to testicular tumors in children: 12 cases and their management. J Urol 1983;129:350-351.

27. Heidenreich A, Bonfig R, Derschum W, et al. A conservative approach to bilateral testicular germ cell tumors. J Urol 1995;153:10-13.

28. Oliver T. Conservative management of testicular germ-cell tumors. Nat Rev Urol 2007;4:550-560.
29. Carmignani L, Gadda F, Gazzano G, et al. High incidence of benign testicular neoplasms diagnosed by ultrasound. J Urol 2003; 170:1783-1786.

30. Giannarini G, Dieckmann KP, Albers P, et al. Organ-sparing surgery for adult testicular tumours: a systematic review of the literature. Eur Urol 2010;57:780-790.

31. Arık A, Uygur C. Testis koruyucu cerrahi. Bull Urooncol 2004;2:6-8.

32. Kabay \$̧. To whom and how to do testis sparing surgery? Bull Urooncol 2011;3:59-62.

33. Haas GP, Shumaker BP, Cerny JC. The high incidence of benign testicular tumors. J Urol 1986;136:1219-1220.

34. Shukla AR, Woodard C, Carr MC, et al. Experience with testis sparing surgery for testicular teratoma. J Urol 2004;171:161-163.

35. Carmignani L, Colombo R, Gadda F, et al. Conservative surgical therapy for Leydig cell tumor. J Urol 2007;178:507-511.

36. Giannarini G, Mogorovich A, Menchini Fabris F, et al. Long-term followup after elective testis sparing surgery for Leydig cell tumors: a single center experience. J Urol 2007;178:872-876.

37. Suardi N, Strada E, Colombo R, et al. Leydig cell tumour of the testis: presentation, therapy, long-term follow-up and the role of organ-sparing surgery in a single-institution experience. BJU Int 2009; 103:197-200.

38. Albers P, Albrecht W, Algaba F, et al. Guidelines on testicular cancer: 2015 update. Eur Urol 2015;68:1054-1068.

39. Albers P, Albrecht W, Algaba F, et al. European Association of Urology guidelines on testicular cancer. 2017. https://uroweb org//guideline/ testicular-cancer Accessed. 2018;2:2018.

40. Krege S, Beyer J, Souchon R, et al. European consensus conference on diagnosis and treatment of germ cell cancer: a report of the second meeting of the European Germ Cell Cancer Consensus group (EGCCCG): part I. Eur Urol 2008;53:478-496.

41. Passarella M, Usta MF, Bivalacqua T], et al. Testicular sparing surgery: a reasonable option in selected patients with testicular lesions. BJU Int 2003;91:337-340.

42. J.S. Valla for the Group D'Etude en Urologie Pédiatrique. Testissparing surgery for benign testicular tumors in children. J Urol 2001; 165:2280-2283.

43. Caldwell BT, Saltzman AF, Maccini MA, Cost NG. Appropriateness for testis-sparing surgery based on the testicular tumor size in a pediatric and adolescent population. J Pediatr Urol 2019;15:70.

44. Steiner H, Höltl L, Maneschg $C$, et al. Frozen section analysis-guided organ-sparing approach in testicular tumors: technique, feasibility, and long-term results. Urology 2003;62:508-153.

45. Heidenreich A, Weissbach L, Höltl W, et al. Organ sparing surgery for malignant germ cell tumor of the testis. J Urol 2001;166:2161-2165.

46. Leroy X, Rigot JM, Aubert S, et al. Value of frozen section examination for the management of nonpalpable incidental testicular tumors. Eur Urol 2003;44:458-460.

47. Giannarini G, Mogorovich A, Bardelli I, et al. Testis-sparing surgery for benign and malignant tumors: A critical analysis of the literature. Indian J Urol 2008;24:467-474. 